Article

\title{
Ergonomic Guidelines of Head-Up Display User Interface during Semi-Automated Driving
}

\author{
Kibum Park ${ }^{1}$ (1) and Youngjae $\operatorname{Im}^{2, *}$ \\ 1 School of Industrial and Management Engineering, Korea University, Seoul 02841, Korea; \\ masterkey@korea.ac.kr \\ 2 Faculty of Human-System Design Engineering, Dong-eui University, Busan 47340, Korea \\ * Correspondence: ergolim@gmail.com
}

Received: 4 March 2020; Accepted: 1 April 2020; Published: 3 April 2020

check for updates

\begin{abstract}
Self-driving vehicles are emerging as a result of technological advances, and the range of human behavior is expanding. The collateral information on driving is increasing, and head-up displays (HUDs) can be coupled with augmented reality displays to convey additional information to drivers in innovative ways. Interference between the actual driving environment and the displayed information can cause distractions. Research is required to find out what information should be displayed and how to properly display it considering the number of information, as well as the location and arrangement of the HUD. This study aims to examine the types of HUD information presentation that enhance the driver's intuitive understanding. The first experiment identified which information affects drivers more in self-driving conditions in terms of error rate and importance. As a result, information that the drivers consider to be of greater importance or more relevant to their safety was selected. The level of HUD information complexity was assessed in the second experiment. The independent variables were the number of symbols, location of the HUD, and arrangement of the HUD. The results showed that the number of symbols was most affected and that fewer than six should be displayed. Besides, the arrangement of contents was more intuitive when a vertical alignment was used, and the main content should be placed in the center of the windshield area. Finally, ergonomic design guidelines of the information presentation type are proposed in this study.
\end{abstract}

Keywords: head-up display; HUD; user interface; ergonomics; information complexity; automated driving; self-driving vehicles; windshield display; infotainment

\section{Introduction}

From past research, a series of guidelines are available to identify human-machine interfaces and to improve the physical and cognitive usability of the product [1]. In particular, the automobile industry needs to simultaneously satisfy the driver's safety and convenience with the special circumstances of the driving environment. With the recent convergence trend with information and communication technology, vehicles are being built with in-vehicle information systems (IVIS) and developed into an interactive communication medium between the vehicle and the driver in real-time, beyond the value of the mobility system [2]. As the development of in-vehicle information systems continues to expand the display area, which provides in-vehicle driving, entertainment, and convenient information, the need is increased for an intuitive and insightful content delivery interface for drivers [3-5].

The level of complexity of information displayed within the vehicle is increasing with the recent advances in self-driving vehicle technology [6]. Thus, the development of a head-up display (HUD) that delivers virtual images to the driver through media such as windshields is continuing, with the driver's range of activities expanding and the display providing information on driving assistance, entertainment, and driver-friendly functions. Due to the development of information and 
communication technology, the HUD emerged as a research topic for conveying virtual information to drivers through augmented reality (AR), such as preventing collisions between pedestrians and vehicles [7]. The HUD improves driving performance more than the head-down display (HDD) and has a higher preference [8,9]. The performance is also affected by the area and layout of the HUD and, trust, confidence, and predictability factors also tend to increase if the HUD is combined with speech and becomes multimodal $[10,11]$. This not only reduces the driver's visual distractions but also improves cognitive judgment [12,13], whereas the overall market demand for HUD, which encompasses windshield and combiner types, is also on a steady rise [14].

With the development of IVIS, such as in-vehicle entertainment and driving assistance systems, the importance of the HUD, which assists the vehicle-to-driver interface, is increasingly being emphasized. However, in driving situations where visual elements are essential, the information provided during driving should be visually recognizable by the driver up to $90 \%$ and the display should be designed to inhibit the distraction of focus in complex systems and to prevent split attention $[15,16]$. Research was carried out providing systematic information on how to commercialize HUDs, human factors, etc. [17]. A study of the interface between the vehicle and the driver by applying $A R$, which provides an intuitive and immersive experience, showed that, although the challenge of perception problems should be solved in the HUD, it reduces response time and increases the likelihood of detecting other hazards [18-21]. HUD-based studies on some elements, such as left-turn and right-turn content, were conducted, but systematic guidelines that include diverse elements and that take safety into account are needed [22,23].

Therefore, if the in-vehicle display overlaps with road information during the driver's process of accepting and manipulating information, an interface design is required to reduce the recognition errors of displayed images and minimize any obstacles to safe driving, such as distractions [24,25]. The HUD needs to be noted as an alternative to an ergonomic design that can provide more diverse information while reducing the divergence of the driver's eyes. To present information considering safety and convenience, organized contextual information is required by type, and element studies related to structured contextual interfaces such as types, functions, and tasks must precede specific visualizations [26,27].

\section{Research Objectives}

The aim of this study is an evaluation of the complexity of information presentation determined by design factors such as the number of information, area of the HUD, and arrangement of the HUD. The ergonomic design guidelines of the HUD are assessed in terms of the driver's performance and workload. The derived guidelines are utilized to construct an interaction method to be used in the future for windshields, whereby the driver remains aware of the driving situation.

This study investigates the complexity of how automotive HUDs are displayed in the windshield. The study was conducted in four stages, as shown in Figure 1. In detail, it was undertaken sequentially by researching HUD contents through literature and market reviews, conducting the first test of selecting information objects to be displayed, while performing the second test on the number of information, area of the HUD, and arrangement of the HUD, as well as drawing out the display method guidelines for the final selected information.

Before the full-scale experiment, a total of 44 factors were selected with 14 factors related to urgency, 14 factors related to general driver information (GDI), and 16 factors related to IVIS based on the automobile market survey and literature survey considering regions such as Europe, Asia, and the Americas. Selected information was firstly selected with a high frequency of investigation in the existing literature [28-32]; however, even though the frequency of the investigation was small, additional information that had a significant safety concern was included.

The purpose of the first experiment was to select the information content displayed on the HUD. The second experiment sought to identify how design variables related to the HUD, including the number of information, area of the HUD, and arrangement of the HUD, affected the driver's response. 


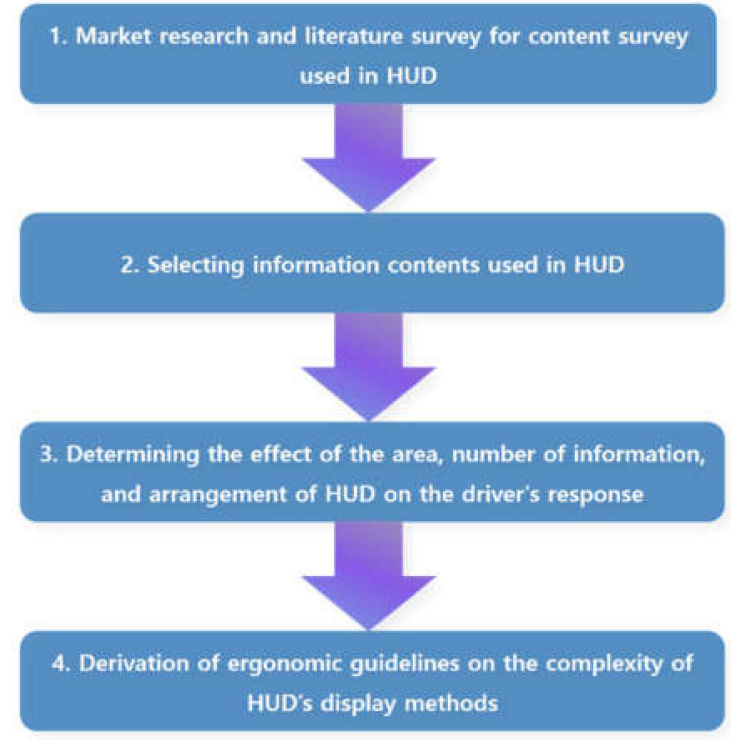

Figure 1. Research flow.

\section{First Experiment}

\subsection{Method}

\subsubsection{Participants}

A total of 21 experimental participants were used to conduct the first test, aged 20 to 54, who mainly drive. They consisted of twelve males and nine females, and the average age was $29.57(\mathrm{SD}=5.29)$ years old. All of the participants can drive, had a driver's license, and had satisfactory eyesight and hearing to do this test. Experimental participants were also recruited to have more than two years of driving experience, and the average driving experience for participants was 5.86 years $(S D=4.51)$. Furthermore, all participants were given enough time to practice in advance.

\subsubsection{Apparatus}

The environment configured for the first test consisted of a driver-centered driving environment through Gridspace's Driving Simulator Equipment GDS-Driving 300/L Model, as shown in Figure 2. Three 43-inch monitors and a 17-inch touchscreen controller, an automatic shift lever, pedals, and gears were built for the experimental environment.

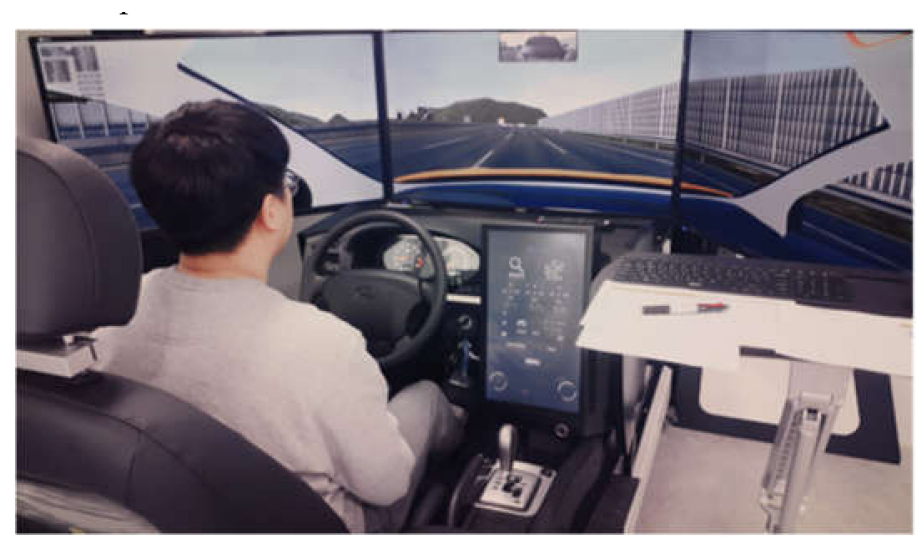

Figure 2. Driving simulator employed in experiment. 


\subsubsection{Experimental Design}

The kind of information that can be displayed on the HUD was selected as the design variable for the experiment. The 44 factors selected based on literature research and market research were re-selected based on the frequency and important issues of safety. As a result, a total of 24 factors were selected for urgency, GDI, and IVIS information, as shown in Table 1. Each factor referred to icons or pictorial shapes used in various regions, including North America, Europe, and Asia, and they were finally presented after being reproduced by visual designers. Each image was redesigned through the designer after referring to properties such as the color and contrast of the ISO standard [33], reviewing the images used in the classification system in the study of the Tretten et al. [7], and considering the images currently used by various automotive manufacturers in various countries.

Table 1. Categorization of factors

\begin{tabular}{cccc}
\hline \multicolumn{4}{c}{ Categorization of factors } \\
\hline No. & Urgency & GDI (General Driver Information) & IVIS (In-Vehicle Information System) \\
\hline 1 & Low window washer fluid & Speedometer & Excessive speed status \\
\hline 2 & Low fuel level & Trip computer & Lane change help \\
\hline 3 & Engine stall & Outside temperature & $\begin{array}{c}\text { Road image at night or poor } \\
\text { weather conditions }\end{array}$ \\
\hline 4 & Oil pressure & Cruise control & External speed control \\
\hline 5 & $\begin{array}{c}\text { Anti-lock braking system } \\
\text { (ABS) failure }\end{array}$ & Multimedia & Road hinders image \\
\hline 6 & Low tire pressure & Phone & Navigator \\
\hline 7 & Door is ajar & Buckle seatbelt reminder & Video of passengers \\
\hline 8 & Malfunctioning light bulb & Which door is ajar & Status of driver \\
\hline
\end{tabular}

Error rates and importance were chosen as the dependent variables for assessing the driver's response. The driver's error rate for information recognition was defined as the rate of frequency at which the driver failed to respond to the information properly or respond when the contents were presented on the windshield while driving.

In addition, importance was defined as the importance level the driver felt for each factor after performing the task of responding when the information was presented on the windshield while driving. The importance was measured as a seven-point Likert scale taking into account the functional aspects of both driving and non-driving situations.

\subsubsection{Experimental Procedure}

The procedure for the first experiment was as follows: at first, the purpose of the study and the main tasks were explained to the participants. The participant highlighted various factors when a total of 24 items were displayed while driving. Next, the error rate and importance level were measured when participants responded to each factor displayed sequentially while driving. Then, a post-interview was conducted to collect subjective data. The error rate was measured as the frequency ratio of cases which were correctly recognized when information was presented on the windshield. The importance level was assessed as the extent to which the driver felt each factor was important after performing the task. Each of the eight factors of Urgency, GDI, and IVIS classification systems was evaluated once, and all participants were given sufficient prior practice time.

\subsection{Results of First Test}

\subsubsection{Error Rate}

The error rate of information in the IVIS classification was relatively higher compared to other classifications. Among them, over-speed status indication (error rate: 0.24), road image display at 
night or in bad atmospheric conditions (error rate: 0.10 ), and speed control considering the external environment (error rate: 0.33 ) were found to be high because of their complex level even within IVIS. For information within the GDI classification, the error rates for trip computers (error rate: 0.10) and cruise control (error rate: 0.10), where information complexity is relatively high, were high compared to other classifications. In the urgency category, for features with the high complexity of information, the driver's mind was not perfectly matched, resulting in a high error rate for oil pressure (error rate: 0.14 ) and low tire pressure (error rate: 0.10 ).

\subsubsection{Importance Level}

Analysis of variance (ANOVA) was performed to determine whether each factor was meaningful in terms of the importance level. The results showed that statistically significant differences for each factor were found $(p<0.001)$. Furthermore, the results of the analysis of importance of each classified factor showed that the information in the urgency group related to safety was relatively important, with a closer relationship to safety denoting higher importance as shown in Figure 3. Factors in the GDI group also showed that safety-related information was more important than additional functions such as multimedia or telephone functions. Finally, in the case of information in the IVIS group, safety-related factors were also was found to be relatively important.

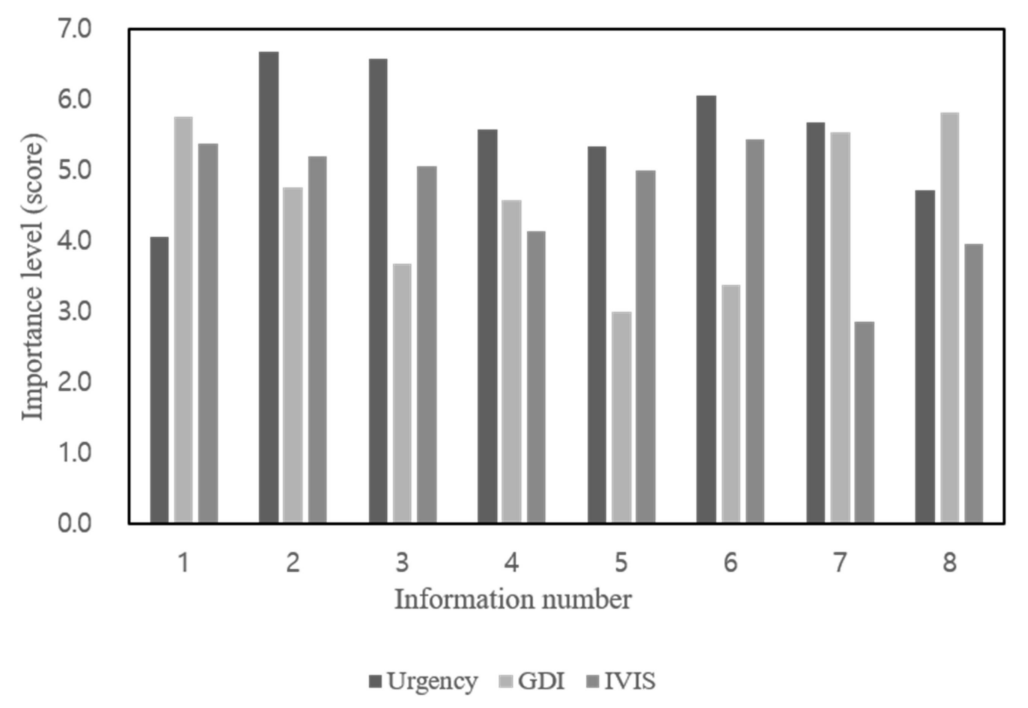

Figure 3. Importance level for each factor.

\section{Second Experiment}

\subsection{Method}

\subsubsection{Participants}

A total of 12 experimental participants were used to conduct the second test, aged 20 to 54 , who mainly drive. They consisted of nine males and three females, and the average age was 27 (SD = 4.31) years old. All of the participants were able to drive, had a driver's license, and had satisfactory eyesight and hearing to do this test. Experimental participants were also recruited to have than two years of driving experience, and the average driving experience for participants was 6.5 years $(\mathrm{SD}=$ 5.14). Four participants had the experience with using an HUD.

\subsubsection{Apparatus}

The driving environment configured for the second test was the same as the driving simulator used in the first test. 


\subsubsection{Experimental Design}

\section{Experimental Variables}

The variables, including the number of information, area of the HUD, and arrangement of the HUD, were selected as the main experimental variables affecting the search for driver information on the windshield. The display area of the HUD was composed of three levels, taking into account the degree of information access effort (IAE) required to change the attention from one area of interest (AOI) to another [24]. As shown in Figure 4, the area variables, defined as left (area 1), middle (area 2), and right (area 3) in this experiment, were positioned horizontally $20 \mathrm{~cm}$ apart, relative to the center area. The area in which each of the alternatives in this experiment was presented was established to account for the characteristics that can be perceived only by eye movements, given the effort for visual attention.

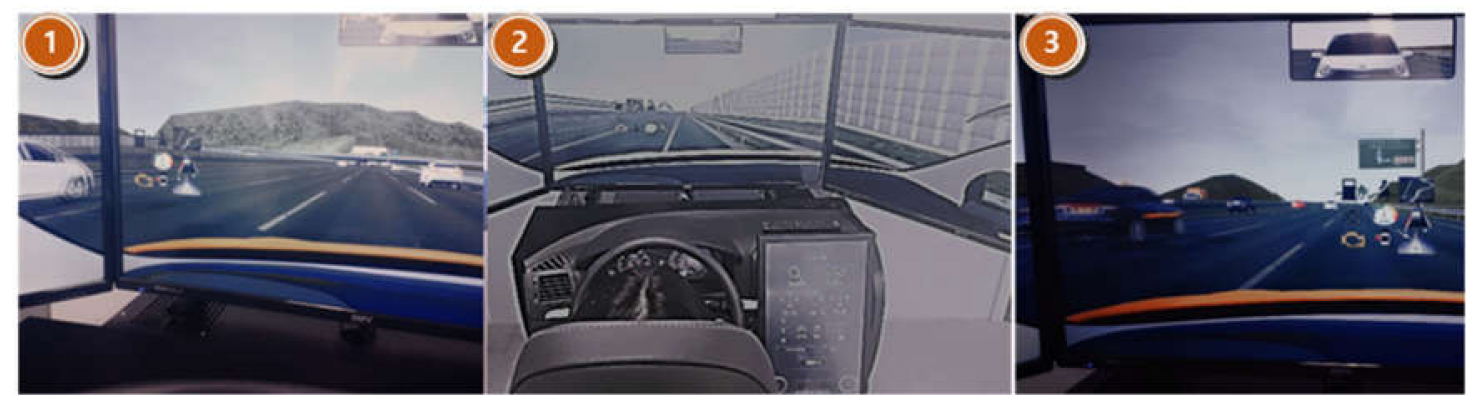

Figure 4. Classification for areas of head-up display (HUD).

In this study, it was assumed that the arrangement of information on the windshield would also affect the visual search response. Based on prior research and market research, it was divided into two array levels [31,32]. In the previous experiment, the characteristics of the information related to urgency were usually referenced to the vertical arrangement in the left-hand area, while those related to GDI or IVIS were relatively diverse. In this experiment, information related to urgency, as shown in Figure 5, was applied with a left vertical arrangement, and the information related to GDI and IVIS was applied with a horizontal and vertical arrangement. Therefore, information related to GDI and IVIS, incorporating this difference, was arranged in two levels, either vertically (arrangement 1 ) or horizontally (arrangement 2).

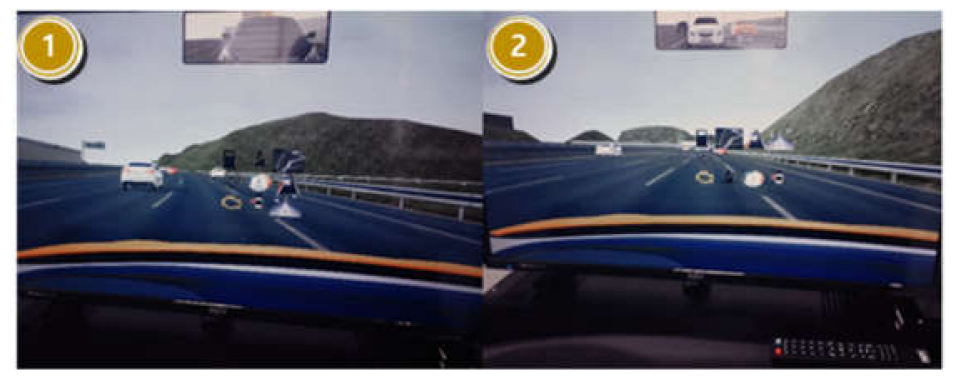

Figure 5. Classification for arrangement of HUD.

The level of the number of information in this experiment allowed defining three levels for information quantity, as shown in Table 2. In detail, the total amount of information at level 1 consisted of three factors, including one each for urgency, GDI, and IVIS classifications. The total amount of information at level 2 consisted of six factors, with two each for the urgency, GDI, and IVIS categories. Finally, the total amount of information at level 3 consisted of nine factors, with three each for urgency, GDI, and IVIS classifications. Therefore, the amount of information included three, six, and nine factors for each level. An example of an alternative display in a real experiment is shown in Figure 6. 
Table 2. Composition of the three levels describing the number of information.

\begin{tabular}{ccccc}
\hline The Level of the Number of Information & Total Factor Quantity & Urgency & GDI & IVIS \\
\hline 1 & 3 & 1 & 1 & 1 \\
\hline 2 & 6 & 2 & 2 & 2 \\
\hline 3 & 9 & 3 & 3 & 3 \\
\hline
\end{tabular}

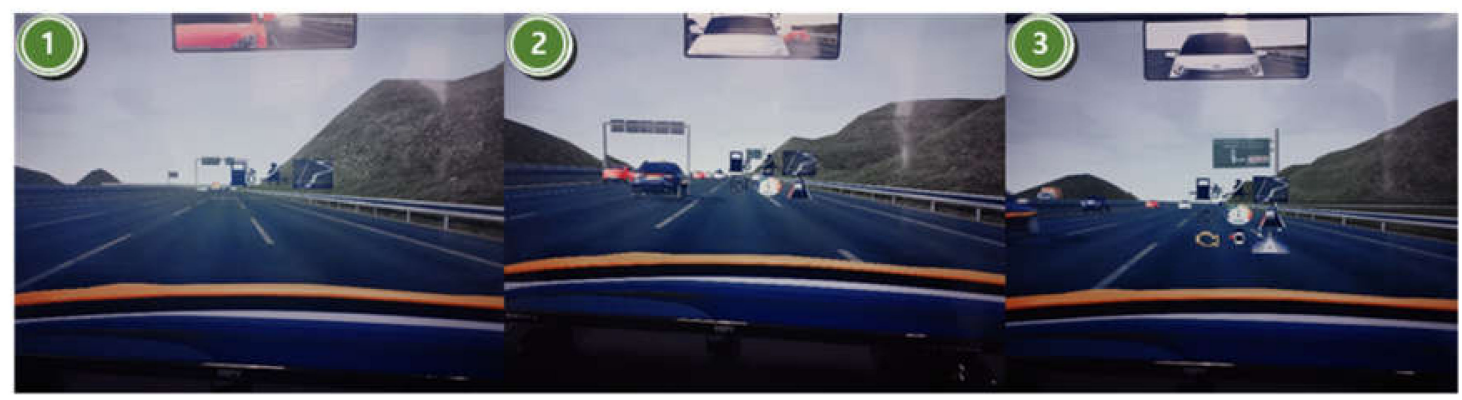

Figure 6. Three levels of information.

Dependent Variables

The response time in this experiment was defined as the time it took to recognize the information. When alternative information was presented to the driver's windshield, this variable was determined by measuring the time it took the driver to respond verbally after recognizing the displayed object. In this experiment, sophistication was added in such a way that the controller automatically recorded the time until the respondent's oral response. Since a change in the number of questions could affect the workload in itself, the number of questions regarding each function was fixed at three per round. The participants were expected to respond with the function name for each question, including factors for urgency, GDI, and IVIS classifications. The modified Cooper-Harper handling scale (MCH) was applied to measure the subjective workload felt by participants [34]. The MCH has a scale of 10 degrees, with larger values denoting greater difficulty. Specifically, a rating of 9-10 requires a redesign because it is difficult to easily accommodate the displayed information, a rating of 6-8 requires improvement in the information displayed to analyze the situation, and a rating of 3-5 requires minor improvement in the information displayed to facilitate decision-making. Lastly, a rating of 1-2 describes a level where information can be displayed to help make decisions.

\subsubsection{Experimental Procedure}

The procedure for the second experiment was firstly described to the participants, along with the purpose of the study and its main tasks, before conducting the designated tests. This task involved identifying and responding to the designated information on the windshield during each round while driving. Next, data on the response time and subjective workload for the task were collected, along with a post-interview. The order of experiments was counterbalanced randomly and repeated 18 times according to the combination of the level of independent variables for each participant (the number of information (3) $\times$ area of the HUD (3) $\times$ arrangement of the HUD (2)). In addition, five minutes of rest were granted every $30 \mathrm{~min}$ to remove the effect of fatigue caused by repeated performance.

\subsection{Results of Second Test}

\subsubsection{Reaction Time}

To determine if each design variable for the reaction time was significant, repeated measures (RM)-ANOVA was performed. Mauchly's spherical test results showed that the significance of the number of information, area of the HUD, and the arrangement of the HUD was greater than 0.05. 
Therefore, a single-variable analysis should be applied, because the experiment satisfied the sphericity requirement. The RM-ANOVA results were found to have significant differences in the number of information, area of the HUD, and arrangement of the HUD at a significance level of 0.05 , as presented in Table 3. Interactions between factors were shown to be insignificant.

Table 3. Repeated measures (RM)-ANOVA results for response time.

\begin{tabular}{cccccc}
\hline Source & SS & df & MS & F & $p$ \\
\hline The number of information & 149.807 & 2 & 74.904 & 115.691 & $<0.000^{* *}$ \\
\hline Area of HUD & 6.001 & 2 & 3.000 & 5.037 & $0.016^{*}$ \\
\hline Arrangement of HUD & 12.097 & 1 & 12.097 & 34.612 & $<0.000^{* *}$ \\
\hline The number of information $\times$ area of HUD & 1.193 & 4 & 0.298 & 0.658 & 0.625 \\
\hline The number of information $\times$ arrangement of HUD & 0.383 & 2 & 0.192 & 0.566 & 0.576 \\
\hline Area of HUD $\times$ arrangement of HUD & 0.285 & 2 & 0.143 & 0.807 & 0.459 \\
\hline The number of information $\times$ area of HUD $\times$ arrangement of HUD & 0.793 & 4 & 0.198 & 0.833 & 0.511 \\
\hline
\end{tabular}

* Significant at $\alpha=0.05,{ }^{* *}$ Significant at $\alpha=0.01$

Firstly, the results for the response time according to the level of the number of information and area of HUD are shown in Figure 7. Responses tended to slow down as the amount of information increased. In the case of the area of HUD, one of the design variables, the response was speedy when area 2, and areas 1 and 3 were relatively slow. The response time between the two areas was also shown to be similar. If the number of information is less than three, it is advisable to present the information in area 2. Additionally, if the number of information is less than six, the main information may be placed in area 2, and the remaining sub-information may be placed in area 1 or area 3 .

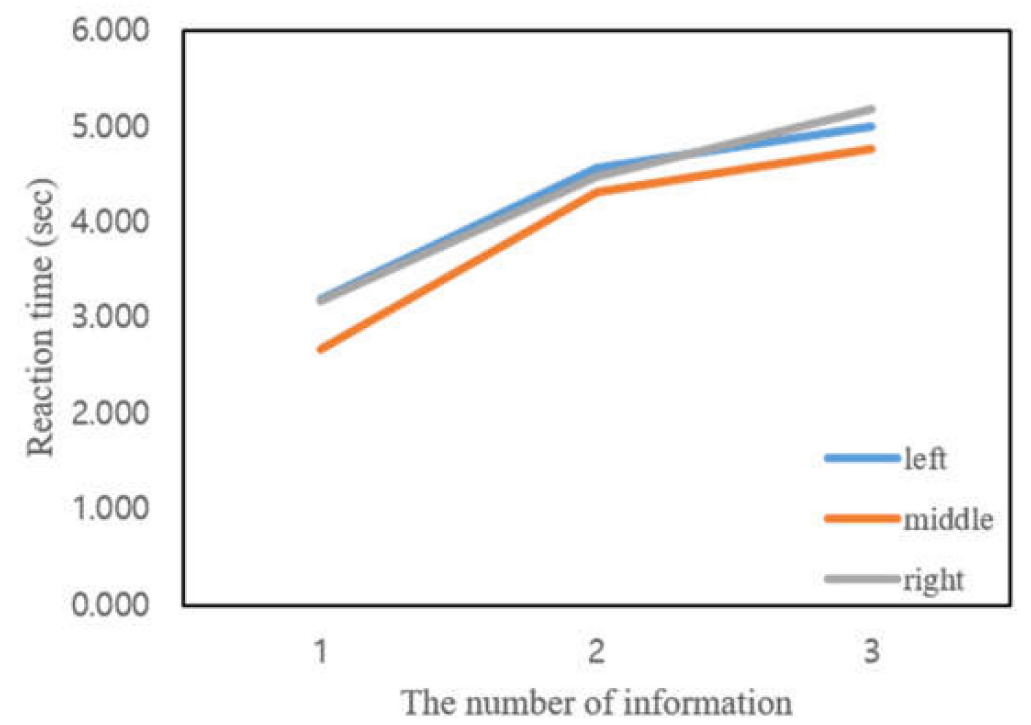

Figure 7. Reaction time according to the level of the number of information and area of HUD.

Next, the results for the response time according to the arrangement of HUD and the level of the number of information are shown in Figure 8. As the amount of information increased, driver response tended to slow down. For the arrangement of HUD design variable, it was shown that the responses were slow with arrangement 2 and fast with arrangement 1 . With regard to the number of information, fewer than six were found to be appropriate, whereas the arrangement of the HUD should be arranged in arrangement 1 rather than in arrangement 2. 


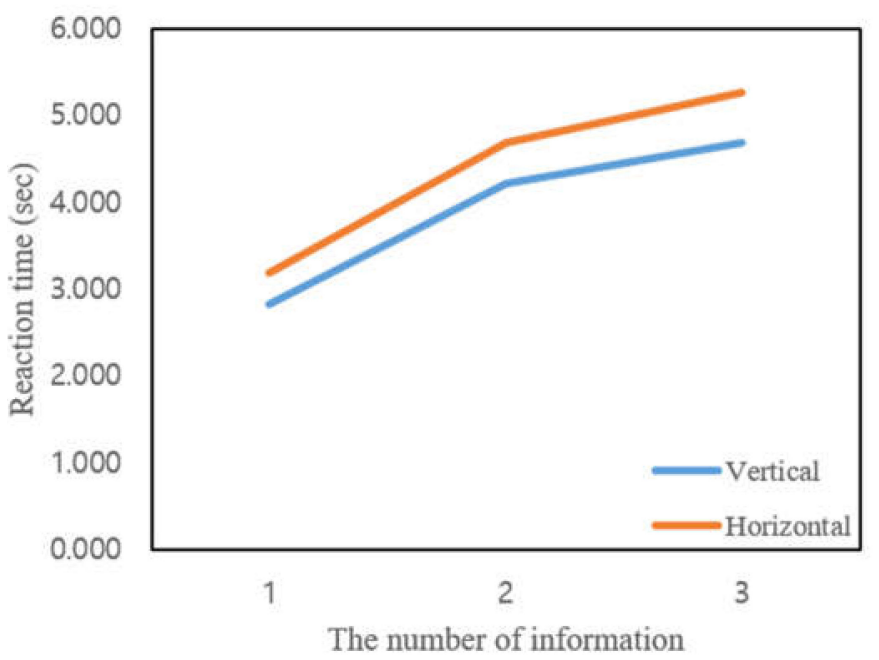

Figure 8. Reaction time according to the level of the number of information and arrangement of HUD.

\subsubsection{Subjective Workload}

To determine if each design variable for the subjective workload was significant, RM-ANOVA was performed. Mauchly's spherical test results showed that the significance of the level of the number of information, area of the HUD, and arrangement of the HUD was greater than 0.05. Therefore, a single-variable analysis should be applied, because the experiment satisfied the sphericity requirement. The RM-ANOVA results were found to have significant differences in the level of the number of information, area of the HUD, and arrangement of the HUD at a significance level of 0.05 , as presented in Table 4. Interactions between factors were shown to be insignificant.

Table 4. RM-ANOVA results for subjective workload.

\begin{tabular}{cccccc}
\hline Source & SS & df & MS & F & $p$ \\
\hline The number of information & 144.009 & 2 & 72.005 & 138.529 & $<0.000^{* *}$ \\
\hline Area of HUD & 9.509 & 2 & 4.755 & 3.883 & $0.036^{*}$ \\
\hline Arrangement of HUD & 5.671 & 1 & 5.671 & 5.037 & $0.046^{*}$ \\
\hline The number of information $\times$ area of HUD & 2.102 & 4 & 0.525 & 2.143 & 0.091 \\
\hline The number of information $\times$ arrangement of HUD & 0.898 & 2 & 0.449 & 1.370 & 0.275 \\
\hline Area of HUD $\times$ arrangement of HUD & 0.454 & 2 & 0.227 & 0.576 & 0.570 \\
\hline The number of information $\times$ area of HUD $\times$ arrangement of HUD & 1.435 & 4 & 0.359 & 1.464 & 0.230 \\
\hline
\end{tabular}

* Significant at $\alpha=0.05,{ }^{* *}$ Significant at $\alpha=0.01$

Firstly, the results for the subjective workload according to the number of information and area of HUD are shown in Figure 9. Subjective workload tended to increase as the amount of information increased. With regard to the area of HUD, the subjective workload was relatively low in area 2, while it was relatively high in areas 1 and 3. Furthermore, the subjective workload between the two areas was shown to be similar. Fewer than six information is appropriate to display, whereas area 2 or area 3 can be used if there is fewer than three information. Moreover, if the number of information is fewer than six, the main information may be placed in area 2, while the remaining sub-information may be placed in area 1 or area 3 .

Next, the results for the subjective workload according to the arrangement of HUD and level of the number of information are shown in Figure 10. As the amount of information increased, subjective workload tended to increase. For the arrangement of HUD design variable, the workload was shown to be high with arrangement 2 , while the workload was small with arrangement 1 . Fewer than 
six information was found to be appropriate, and it was recommended that the arrangement of the HUD should feature one layout rather than two.

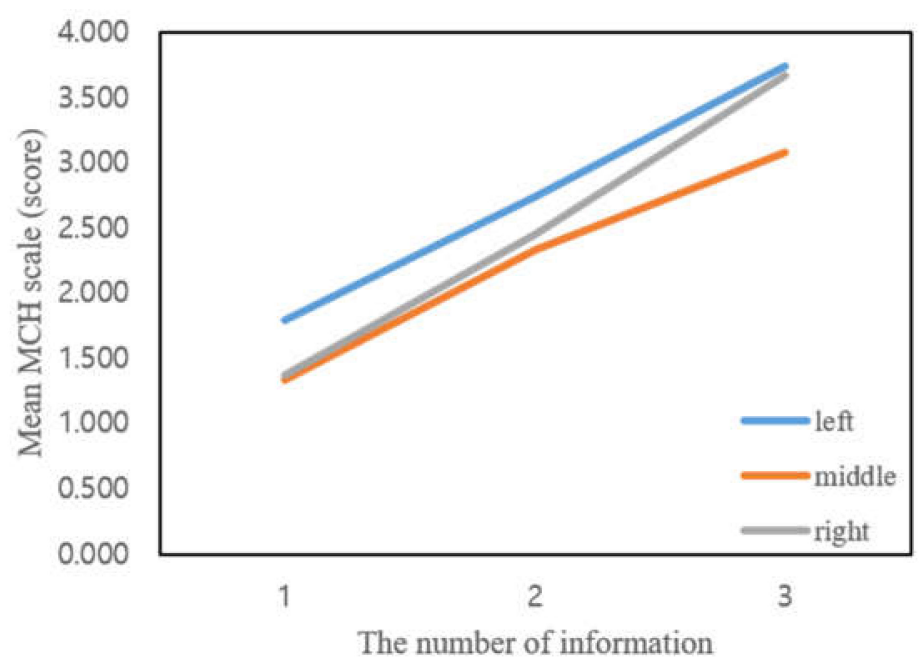

Figure 9. Modified Cooper-Harper handling (MCH) scale according to the level of the number of information and area of HUD.

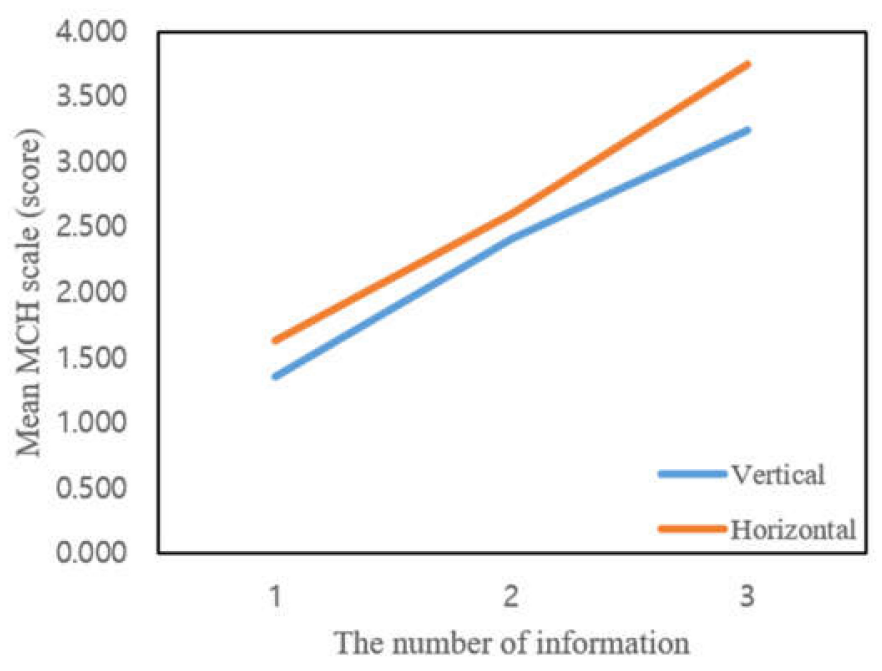

Figure 10. MCH scale according to the level of the number of information and arrangement of HUD.

\section{Discussion}

Although HUD-related technologies are becoming increasingly commercialized, they should be presented in appropriate areas, taking into account the specific nature of the driving situation and driver safety. Therefore, the HUD area should be classified to include restricted and expandable areas, not limited to the optimal layout, and this should be applied in an informational manner that is intuitive for the driver and reduces the workload of drivers. Issues concerning the safety of HUDs, such as focal distance or external object perception, as well as object-road and object-object overlap, can have a significant negative impact. Therefore, HUD usability studies should be conducted within appropriate methodological paradigms and experimental designs. Moreover, AR still faces a number of technical challenges, and human factors should also be addressed [35,36].

The concept of HUDs was raised for decades, but they were found to be difficult to apply to vehicles other than airplanes [37]. The safety benefits of HUDs are generally small, and, in some instances, HUDs produce poorer performance [38]. After the evolution of self-driving technology, 
image display through AR has the potential to enhance road safety, induce intuitive driving activities, and improve driving experience. However, the AR technology level, applicable area, luminance, etc. should be more developed. Relevant studies are still being performed through driving simulators rather than in a real road environment [38-40]. Based on past research, it is important to consider driver safety and visual distractions in HUD design [37]. Relevant studies on the display area of HUD information also examined the driver's response to each HUD area and provided design guidelines for the driver's preferred area. Several prior studies analyzed driver response time and preference changes depending on the display area of the warning image presented on the HUD [41]. Summing up the results of the HUD preference areas presented in the relevant study showed that areas in the left and right directions, with the driver's seat as the reference center, performed well and were preferable. These results were consistent at a certain level in terms of the results and trends derived from this study. However, unlike several previous studies that identified differences in driver preference depending on the location of the HUD image, the study in Park et al. [24] showed that performance in the lower left or lower right areas was found to be relatively low after considering detailed investigation results specific to the driver's windshield; thus, this study applied three horizontal areas.

For this reason, the task presented in this study firstly involved recent information considering technology trends in semi-automated driving situations, resulting in a difference in difficulty compared to the situation of staring at simple roads, as applied in previous studies. This presented a difference with existing studies using simple or fixed forms of visual images, such as warning displays. For example, the study in Park et al. [41] looked at changes in driver preference depending on the location of the HUD image by performing object navigation and selection on a single-line scrolling list while driving. However, this study provided the driver with a more interactive situation with a task difficulty that appropriately reflects the variability of driver distraction to the same extent as an actual driving situation, while not interfering with the road operation.

On the other hand, in experiments that gave drivers warning signs and recognized responses, such as the study by Morita et al. [42], the middle area was found to be optimal to perform object navigation and selection, although areas below $4^{\circ}-5^{\circ}$ were most preferred compared to the middle area. This result was consistent with the optimal area, i.e., the middle area, found in the study of HUD speedometer recognition and control by aircraft pilots [43]. Thus, as cognitive workload increases, the middle area can be interpreted as optimal. Next, there were differences in results depending on whether the task was assigned only on the driver-side windshield area. Considering only the driver-side windshield area, a more spatial, specific area investigation is possible, and the accuracy of the task itself can be increased by minimizing driver distraction. Wittmann et al. [44] revealed that the preferred range was not derived at various levels when the range of areas on the driver's side was addressed in a wider area than the windshield. The results of another study [7] that dealt only with driver-side windshield areas showed that the preferred area is not only in the middle but also along the horizontal axis, resulting in similar results to those of this study.

The HUD design guidelines we presented were tested by assuming that the information is basically provided in self-driving mode only. In our previous study [24], classifying the area of the HUD in semi-automated driving conditions showed that using horizontal central areas does not cause usability problems for the driver's response. The tendency to increase the search time as more objects were found was similarly considered $[45,46]$. Therefore, this study, which examined the complexity of how displays with multiple content are presented, arrayed three to nine information per area to maintain a certain level of difficulty in the experimental task without driving overload. Previous studies [47-49] found that the use of an HUD increases subjective safety but does not cause excessive distraction, and that the actual response time for speed limit tasks was better derived. Furthermore, relevant studies $[50,51]$ showed that various information resources are more accessible to drivers than when using an HDD (head-down display). The comparison analysis was conducted by focusing on using the HUD under both low and high driving workload [52]. Specifically, the driver's response using the HUD was 
better in terms of vehicle control behavior (i.e., variance in steering wheel angle and mean lateral lane position) and the driver's attention demands (i.e., variance in lateral acceleration).

A review of how information is presented, including visual elements of the HUD, such as location, arrangement, and color, showed that a two-dimensional image of distance intuitively provided to the driver has a low workload [53]. A leading study of information types and levels of numbers in the HUD showed more than double the response time as the number increased from four to seven [13,47]. In this study, the number of information was fewer than six, showing similar results. A study looking at the display area and arrangement [54] placed driving-related content on the driver-side windshield and multimedia functions such as the Internet on the central windshield. In this study, the scope of the area was limited to the driver-side windshield; thus, the main content was placed in area 2 and other content was placed in area 1 and area 3 . In addition, this study confirmed the result of similar workload occurring between areas 1 and 3. Furthermore, some studies examined the perception of the size and arrangement of the information displayed in the HUD [55]; however, the priority or influence degree of the levels of the of information, area, and arrangement was different from this study, because it was difficult to grasp. In particular, with regard to the arrangement of the HUD, the final selection of the vertical and horizontal type was made by considering the different arrangement methods investigated by Cho et al. [31]. Thus, the selected information in this study showed that the vertical type was slightly better than the horizontal type. However, the arrangement factor was less influential than the other design variable, i.e., the amount of information. This result could be changed depending on the type of information.

There were some limitations of this study. Not all of the design variables affecting the driver were considered in this study, as the level of display, optics, and information and communication technologies are constantly evolving; thus, some issues that are affected by technology trends when it comes to the degree of practicability of complexity for their expression were not considered. Next, the restriction of distraction with respect to the driver's eyes increases the accident rate after 1.5 to $2 \mathrm{~s}$; thus, it is not feasible to immediately increase the display complexity when self-driving technology is not sufficiently advanced [56]. Because this experiment was conducted on a driving simulator, we made an effort to mirror the environment using a windshield in a real vehicle. To verify the effect of individual difference, a statistical analysis of gender effect was conducted. The results of the $t$-test showed that the effect of the gender group on response time was not statistically significant $(p=0.131)$. The average response times for men and women were $4.21 \pm 1.11$ and $3.96 \pm 0.98$, respectively. This study focused on the derivation of general design guidelines for HUDs. Although this experiment was performed in a highway driving environment, other factors such as traffic density or road conditions should be further considered.

Depending on the preference of the driver's level of information acceptance, the information displayed in the HUD may receive a negative response. To address this, an adaptable interface design should be introduced to take into account the factors that can inspire user experience by considering those who prefer low information acceptance $[57,58]$. The adaptable interface design can be appropriately considered for intuitiveness and safety, which familiarizes the driver with the context for vehicle information. For example, it is more necessary to facilitate drivers with GDI and IVIS than urgent information. Thus, adaptive interfaces should be provided to fulfill the type of information and the extent of driver acceptance. Although this study classified the information in terms of urgency, GDI, and IVIS based on the literature review, there may be more diverse dimensions such as severity or infotainment. Moreover, further studies of HUD representation require an ongoing review to identify priorities for design variables and to highlight upcoming technical situations reflecting AR.

\section{Conclusions}

The detailed results of this study were as follows: firstly, when considering the proper area of the windshield, the design variable showed that the level of the number of information displayed has a greater effect than the area of the HUD or the arrangement of the HUD. The number of information 
presented should be fewer than 6. Furthermore, the main information should be presented on the driver's central side, and the sub-information should be displayed on the left and right sides of the driver's horizontal area of the windshield. As for the arrangement method, vertical arrangements were found to be more intuitive to the driver than horizontal ones. However, since its influence degree was lower than that of the level of the number of information, the information should be selected based on the arrangement of the HUD according to its attributes.

The results of this study are expected to be a basic representation of the proper area classification and complexity of display methods when HUD information is displayed to drivers in a vehicle. In addition, road environment variables and more diverse information should be continuously reviewed using equipment such as eye trackers. Therefore, it is necessary to study the mode of display presentation considering the driver's response and distraction in actual vehicles. Further research is also required to take into account a wider variety of scenarios and information presentation methods applicable in future operational situations.

Author Contributions: Conceptualization, K.P. and Y.I.; methodology, Y.I.; writing-original draft preparation, K.P.; writing - review and editing, K.P, and Y.I. All authors have read and agreed to the published version of the manuscript.

Funding: This research received no external funding.

Conflicts of Interest: The authors declare no conflicts of interest.

\section{References}

1. Wagner, D.; Birt, J.A.; Snyder, M.D.; Duncanson, J.P. Human Factors Design Guide for Acquisition of Commercial-off-the-Shelf Subsystems, Non-Developmental Items, and Developmental Systems; No. DOT/FAA/CT-96/1; DOT, FAA Technical Center: Atlantic City, NJ, USA, 1996. [CrossRef]

2. Kohlhaas, R.; Schamm, T.; Lenk, D.; Zöllner, J.M. Towards driving autonomously: Autonomous cruise control in urban environments. In Intelligent Vehicles Symposium (IV); IEEE: Gold Coast, Australia, 2013; pp. 116-121. [CrossRef]

3. Gabbard, J.L.; Fitch, G.M.; Kim, H. Behind the Glass: Driver Challenges and Opportunities for AR Automotive Applications. Proc. IEEE 2014, 102, 124-136. [CrossRef]

4. Lee, J.M.; Ju, D.Y. Prioritization analysis for contents sensibility evaluation of the future mobility. Korean J. Sci. Emot. Sensib. 2018, 21, 3-16. [CrossRef]

5. Park, K.; Jung, E.S.; Im, Y. Affective Design of Automotive Center Fascia Display: Focused on Regional Preference. J. Ergon. Soc. Korea 2019, 38, 279-289. [CrossRef]

6. SAE. Automated Driving: Levels of Driving Automation Are Defined in New SAE International Standard J3016; Society of Automotive Engineers: Warrendale, PA, USA, 2014.

7. Tretten, P. Information Design Solutions for Automotive Displays: Focus on HUD. Ph.D. Thesis, Luleå Tekniska Universitet, Luleå, Sweden, 2011.

8. Shahriar, S.T.; Kun, A.L. Camera-View Augmented Reality: Overlaying Navigation Instructions on a Real-Time View of the Road. In Proceedings of the 10th International Conference on Automotive User Interfaces and Interactive Vehicular Applications-AutomotiveUI, Toronto, ON, Canada, 23-25 September 2018; Volume 18, pp. 146-154. [CrossRef]

9. Topliss, B.H.; Pampel, S.M.; Burnett, G.; Gabbard, J.L. Evaluating Head-Up Displays across Windshield Locations. In Proceedings of the 11th International Conference on Automotive User Interfaces and Interactive Vehicular Applications-AutomotiveUI, Utrecht, The Netherlands, 22-25 September 2019; Volume 19, pp. 244-253. [CrossRef]

10. Häuslschmid, R.; Ren, D.; Alt, F.; Butz, A.; Höllerer, T. Personalizing Content Presentation on Large 3D Head-Up Displays. PRESENCE Virtual Augment. Real. 2019, 27, 80-106. [CrossRef]

11. Large, D.R.; Kim, H.; Merenda, C.; Leong, S.; Harvey, C.; Burnett, G.; Gabbard, J. Investigating the effect of urgency and modality of pedestrian alert warnings on driver acceptance and performance. Transp. Res. Part F Traffic Psychol. Behav. 2019, 60, 11-24. [CrossRef]

12. Kim, K.H.; Jang, J.C.; Han, S.C. Current Status and Prospect of Automotive Augmented Reality. In KEIT PD Issue Report; KEIT: Daegu, Korea, 2015; pp. 13-29. 
13. Häuslschmid, R.; Osterwald, S.; Lang, M.; Butz, A. Augmenting the Driver's View with Peripheral Information on a Windshield Display. In Proceedings of the 20th International Conference on Intelligent User Interfaces ACM, Atlanta, GA, USA, 29 March-1 April 2015; pp. 311-321. [CrossRef]

14. Brian, R. Vehicle Displays and Interfaces Symposium. Burton Manor Conference Center Livonia; Automotive IQ: Berlin, Germany, 2016.

15. Beggiato, M.; Hartwich, F.; Schleinitz, K.; Krems, J.; Othersen, I.; Petermann-Stock, I. What would drivers like to know during automated driving? Information needs at different levels of automation. In Proceedings of the 7. Tagung Fahrerassistenzsysteme, Munich, Germany, 25-26 November 2015.

16. Wickens, C.D.; Hollands, J.G.; Banbury, S.; Parasuraman, R. Engineering Psychology E Human Performance; Psychology Press: Hove, UK, 2015.

17. Naujoks, F.; Purucker, C.; Wiedemann, K.; Marberger, C. Noncritical State Transitions during Conditionally Automated Driving on German Freeways: Effects of Non-Driving Related Tasks on Takeover Time and Takeover Quality. Hum. Factors 2019. [CrossRef]

18. Bark, K.; Tran, C.; Fujimura, K.; Ng-Thow-Hing, V. Personal Navi: Benefits of an Augmented Reality Navigational Aid Using a See-Thru 3D Volumetric HUD. In Proceedings of the 6th International Conference on Automotive User Interfaces and Interactive Vehicular Applications, Seattle, WA, USA, 17-19 September 2014; pp. 1-8. [CrossRef]

19. Schneider, M.; Bruder, A.; Necker, M.; Schluesener, T.; Henze, N.; Wolff, C. A field study to collect expert knowledge for the development of AR HUD navigation concepts. In Proceedings of the 11th International Conference on Automotive User Interfaces and Interactive Vehicular Applications Adjunct Proceedings-AutomotiveUI, Utrecht, The Netherlands, 22-25 September 2019; Volume 19, pp. 358-362. [CrossRef]

20. Eyraud, R.; Zibetti, E.; Baccino, T. Allocation of visual attention while driving with simulated augmented reality. Transp. Res. Part F Traffic Psychol. Behav. 2015, 32, 46-55. [CrossRef]

21. Rusch, M.L.; Schall, M.C.; Gavin, P.; Lee, J.D.; Dawson, J.D.; Vecera, S.; Rizzo, M. Directing driver attention with augmented reality cues. Transp. Res. Part F Traffic Psychol. Behav. 2013, 16, 127-137. [CrossRef]

22. Na, J.Y.; Baek, S.D.; Heo, J.Y. Head-Up Display (HUD) Interface Design of Navigation co-nsidering User's Decision Context. In Proceedings of the 5th HCI KOREA, Jeongsun, Kangwon, Korea, 8-10 Feburary 2017.

23. Meixner, G.; Häcker, C.; Decker, B.; Gerlach, S.; Hess, A.; Holl, K.; Klaus, A.; Lüddecke, D.; Mauser, D.; Orfgen, M.; et al. Retrospective and future automotive infotainment systems-100 years of user interface evolution. In Automotive User Interfaces; Springer: Cham, Switzerland, 2017; pp. 3-53. [CrossRef]

24. Park, K.B.; Jung, E.S.; Ban, K.M.; Im, Y.J. A Study about classification of the areas of Head-Up Display(HUD) on Driving. J. Ergon. Soc. Korea 2018, 37. [CrossRef]

25. Von Sawitzky, T.; Wintersberger, P.; Riener, A.; Gabbard, J.L. Increasing trust in fully automated driving: Route indication on an augmented reality head-up display. In Proceedings of the 8th ACM International Symposium on Pervasive Displays-PerDis, Palermo, Italy, 12-14 June 2019; Volume 19, pp. 1-7. [CrossRef]

26. Park, J.W.; Kim, J.; Park, J.; Lee, Y.J.; Lee, Y.J. Information Design of Smart Car Navigation based on Driving Context. In Proceedings of the 61th Transactions of the Korean Society of Automotive Engineers, Jeju, Korea, 19-21 May 2016.

27. Park, K.B. A Study on the Type of Information Presentation for the Head Up Display in Passenger Vehicles. Master's Thesis, Korea University, Seoul, Korea, 2019. [CrossRef]

28. Hong, S.P.; Kim, S.M.; Park, S.J.; Jung, E.S. A Study on Designing of a Menu Structure for the Instrument Cluster IVIS using Taguchi Method. J. Ergon. Soc. Korea 2010, 29, 39-46. [CrossRef]

29. Gu, B.R.; Ju, D.Y. Comparative Analysis of Requirements for Information Presentation on In-vehicle Display Systems by Driving Career. Korean Soc. Automot. Eng. 2016, 24, 668-676. [CrossRef]

30. Lee, Y.H.; Yoo, H.S.; Pan, Y.H. Content Guidelines for Multi-Display User Experience in Autonomous Vehicles. J. Ergon. Soc. Korea 2017, 36. [CrossRef]

31. Cho, Y. Augmented Reality (AR) Head-Up Display (HUD) Design Study for Prevention of Car Accident Based on Graphical Design, Sensitivity and Conveyance of Meaning. Arch. Des. Res. 2015, 28, 103-117. [CrossRef]

32. Wu, H.; Shou, S. Automotive Cockpit Design 2020; Chalmers University of Technology Department of Product and Production Engineering Division of Design and Human Factors: Göteborg, Sweden, 20 November 2011. 
33. DIN EN ISO 15008. Straßenfahrzeuge-Ergonomische Aspekte von Fahrerinformations und Assistenzsystemen-Anforderungen und Bewertungsmethoden der Visuellen Informationsdarstellung im Fahrzeug; DIN Deutsches Institut für Normung: Berlin, Germany, 2009.

34. Wierwille, W.W.; Casali, J.G. A validated rating scale for global mental workload measurement applications. In Proceedings of the 27th Human Factors Society Annual Meeting, 10-14 October 1983; Sage Publications: Norfolk, Virginia, USA; Volume 27, pp. 129-133. [CrossRef]

35. Riener, A.; Kun, A.L.; Gabbard, J.; Brewster, S.; Riegler, A. ARV 2018: 2nd Workshop on Augmented Reality for Intelligent Vehicles. In Proceedings of the 10th International Conference on Automotive User Interfaces and Interactive Vehicular Applications-AutomotiveUI, Toronto, ON, Canada, 23-26 September 2018; Volume 18, pp. 30-36. [CrossRef]

36. Tufano, D.R. Automotive HUDs: The Overlooked Safety Issues. Hum. Factors 1997, 39, 303-311. [CrossRef] [PubMed]

37. Nicholas, J. Ward, Andrew Parkes, Head-up displays and their automotive application: An overview of human factors issues affecting safety. Accid. Anal. Prev. 1994, 26, 703-717.

38. Gish, K.W.; Staplin, L. Human Factors Aspects of Using Head UP Displays in Automobiles: A Review of the Literature; DOT HS 808 320; NHTSA: Washington, DC, USA, 1995.

39. Kun, A.L.; Tscheligi, M.; Riener, A.; van der Meulen, H. ARV 2017: Workshop on Augmented Reality for Intelligent Vehicles. In Proceedings of the 9th International Conference on Automotive User Interfaces and Interactive Vehicular Applications Adjunct-AutomotiveUI 2017, Oldenburg, Germany, 24-27 September 2017; Volume 75, pp. 47-51. [CrossRef]

40. Jesus, V.; Gilberto, O.-G. Methodology for the design of automotive HUD graphical interfaces. DYNA 2018, 85, 161-167. [CrossRef]

41. Park, J.; Cho, C.; Baek, S.; Park, W. Effect of automotive head-up display (HUD) imagery location on driver preference associated with use of scrolling list while driving. In Proceedings of the 19th Triennial Congress of the International Ergonomics Association, Melbourne, Australia, 9-14 August 2015.

42. Morita, K.; Sekine, M.; Tsukada, Y.; Okada, T.; Toyofuku, Y. Consideration on Appropriate Display Area for Head-Up Displays; SAE Technical Paper No. 2007-01-3512; SAE: Warrendale, PA, USA, 2007. [CrossRef]

43. Weintraub, D.J.; Haines, R.F.; Randle, R.J. Head-up display (HUD) utility, II: Runway to HUD transitions monitoring eye focus and decision times. In Proceedings of the 29th Human Factors Society Annual Meeting, Baltimore, MD, USA, 29 September-3 October 1985; SAGE Publications: Thousand Oaks, CA, USA; Volume 29, pp. 615-619. [CrossRef]

44. Wittmann, M.; Kiss, M.; Gugg, P.; Steffen, A.; Fink, M.; Pöppel, E.; Kamiya, H. Effects of display position of a visual in-vehicle task on simulated driving. Appl. Ergon. 2006, 37, 187-199. [CrossRef]

45. Nunes, A.; Wickens, C.; Yin, S. Examining the viability of the Neisser search model in the flight domain and the benefits of highlighting in visual search. In Proceedings of the 50th Human Factors and Ergonomics Society Annual Meeting, San Francisco, CA, USA, 16-20 October 2006; Sage Publications: Thousand Oaks, CA, USA; Volume 50, pp. 35-39. [CrossRef]

46. Remington, R.W.; Johnston, J.C.; Ruthruff, E.; Gold, M.; Romera, M. Visual search in complex displays: Factors affecting conflict detection by air traffic controllers. Hum. Factors 2000, 42, 349-366. [CrossRef]

47. Donkor, G.E. Evaluating the impact of Head-Up Display complexity on peripheral detection performance: A driving simulator study. Adv. Transp. Stud. 2012, 28, 5-16.

48. Plavšic, M.; Duschl, M.; Tönnis, M.; Bubb, H.; Klinker, G. Ergonomic design and evaluation of augmented reality based cautionary warnings for driving assistance in urban environments. Proc. Int. Ergon. Assoc. 2009.

49. Tonnis, M.; Klinker, G. Effective control of a car driver's attention for visual and acoustic guidance towards the direction of imminent dangers. In Proceedings of the 2006 IEEE/ACM International Symposium on Mixed and Augmented Reality, Santa Barbard, CA, USA, 22-25 October 2006; pp. 13-22. [CrossRef]

50. Doshi, A.; Cheng, S.Y.; Trivedi, M.M. A novel active heads-up display for driver assistance. IEEE Trans. Syst. Man Cybern. Part B Cybern. 2008, 39, 85-93. [CrossRef] [PubMed]

51. Haeuslschmid, R.; Shou, Y.; O’Donovan, J.; Burnett, G.; Butz, A. First steps towards a view management concept for large-sized head-up displays with continuous depth. In Proceedings of the 8th International Conference on Automotive User Interfaces and Interactive Vehicular Applications, Ann Arbor, MI, USA, 24-26 October 2016; pp; pp. 1-8. [CrossRef] 
52. Liu, Y.C. Effects of using head-up display in automobile context on attention demand and driving performance. Displays 2003, 24, 157-165. [CrossRef]

53. Wang, C.W.; Jung, H.Y.; Na, Y.J.; Min, S.D. Analysis of Brain activity quotient change of HUD location and Color. In Proceedings of the 46th Journal of Korean Institute of Electrical Engineers, Muju, Jeonbuk, Korea, 15-17 July 2015.

54. Betancur, J.A. Physical Variable Analysis Involved in Head-Up Display Systems Applied to Automobiles. In Augmented Reality-Some Emerging Application Areas; InTech. ISO: Romana, Croatia, 2011; p. 690. [CrossRef]

55. Kim, M.J.; Pan, Y.H. A Study on the relationship between cognitive level and size according to the importance of vehicle Head-Up Display channeled information. J. Korea Des. Knowl. 2015, 33, 163-170.

56. Klauer, S.G.; Dingus, T.A.; Neale, V.L.; Sudweeks, J.D.; Ramsey, D.J. The Impact of Driver Inattention on Near-Crash/Crash Risk: An Analysis Using the 100-Car Naturalistic Driving Study Data; National Highway Traffic Safety Administration: Washington, DC, USA, 2006.

57. Ulahannan, A.; Cain, R.; Thompson, S.; Skrypchuk, L.; Mouzakitis, A.; Jennings, P.; Birrell, S. User expectations of partial driving automation capabilities and their effect on information design preferences in the vehicle. Appl. Ergon. 2020, 82. [CrossRef] [PubMed]

58. Ulahannan, A.; Jennings, P.; Oliveira, L.; Birrell, S. Designing an Adaptive Interface: Using Eye Tracking to Classify How Information Usage Changes over Time in Partially Automated Vehicles. IEEE Access 2020, 8, 16865-16875. [CrossRef]

(C) 2020 by the authors. Licensee MDPI, Basel, Switzerland. This article is an open access article distributed under the terms and conditions of the Creative Commons Attribution (CC BY) license (http://creativecommons.org/licenses/by/4.0/). 